\title{
Designing a Revenue Sharing Contract under Information Asymmetry
}

\author{
Jaimini Bhattacharyya \\ Department of Management Studies, \\ Indian Institute of Technology Madras, Chennai 600036, India. \\ E-mail: ms14d008@smail.iitm.ac.in \\ Rahul R. Marathe \\ Department of Management Studies, \\ Indian Institute of Technology Madras, Chennai 600036, India. \\ Corresponding author: rrmarathe@iitm.ac.in \\ G. Srinivasan \\ Department of Management Studies, \\ Indian Institute of Technology Madras, Chennai 600036, India. \\ E-mail: gsrini@iitm.ac.in
}

(Received April 9, 2020; Accepted May 19, 2020)

\begin{abstract}
In a supply chain coordinated by a revenue sharing contract, under-reporting of sales revenue has been a common practice amongst retailers who always have private information about the market demand. In this article, we aim to design a mechanism to mitigate this problem. One may design a contract to elicit truthful information from the retailer while maximizing supplier's payoff. However, we find that such contracts fail to coordinate the supply chain, when the market demand is high. Hence, we study an audit-based revenue sharing contract. First, we design a laboratory experiment to investigate the impact of retailer's decisions on the subsequent choices made by the supplier. We find that the audit probability chosen by the supplier increases with the gap between retailer's order quantity and the sales reported by the retailer. We follow this up with a simulation experiment which incorporates the findings of our laboratory experiment. Audit cost and the penalty announced by the supplier for not reporting true sales turned out to be important in making decisions for both the players. We also find the threshold auditing cost beyond which auditing is not economically viable for the supplier.
\end{abstract}

Keywords- Supply chain, Revenue sharing contract, Information asymmetry, Dishonesty.

\section{Introduction}

In a revenue sharing contract, the problem of under-reporting of sales is common when a retailer possesses private information about demand. This information provides him (without loss of generality, we refer to the retailer as "he" and the supplier as "she") scope to understate sales. Under-reporting sales figure results in the retailer transferring lower than the contracted share of the revenue to the supplier. This underreporting of sales can be termed as cheating on part of the retailer (Heese and Kemahlioglu-Ziya, 2014). This problem has been extensively studied in the contract theory literature.

Two major approaches have been proposed towards the solution of this problem: The first approach is to elicit private information from the informed player; while the second is to discourage the informed player from cheating. With the first approach, various mechanisms have been proposed for the principal (the uninformed party, that is, the supplier in our case) based on the principles of individual rationality (IR) and incentive compatibility (IC) to elicit truthful information from the 
International Journal of Mathematical, Engineering and Management Sciences

Vol. 5, No. 5, 820-834, 2020

https://doi.org/10.33889/IJMEMS.2020.5.5.064

agent (the informed party e.g. the retailer in our case). For example, Arya and Mittendorf (2004) propose a return policy in the quantity contract to know the exact demand; Corbett and de Groote (2000), Corbett (2001), Corbett and Tang (1999), Ha (2001) address the issue of an agent holding private information about cost; Corbett et al. (2004), and Burnetas et al. (2007) address the issue of inflating forecast by the agent (supplier) to the principal (manufacture) in order to get higher capacity allocation. However, one basic assumption of these studies is that the demand distribution is common knowledge to the parties in the supply chain. In this work, we have assumed asymmetry in the demand distribution between the players. This is a reasonable assumption since, in this era of globalization when the firms are based in different locations across the world, the supplier's belief about the market demand may be different from the information available with the retailer.

The second approach addresses this problem by designing audit policy and punitive measures in the revenue sharing contract. Under these mechanisms, the contract provides the principal the right to audit the revenue reports based on pre-determined criteria. This approach is majorly adopted to study the problem of tax evasion and design framework for a regulatory body. Within this context of tax evasion, Baron and Besanko (1984), Laffont and Tirole (1986) consider a regulator's perspective where the agent reports its cost structure for a product; Kaplow and Shavell (1994) propose a solution to enable self-reporting of crimes by an individual; Kofman and Lawarree (1993) address the problem of an agent colluding the internal auditor where the audit process is not foolproof; Skinner and Slemrod (1985), Crocker and Slemrod (2005), Sandmo (2005) model the tax enforcement perspective. Our scenario differs from the above as in our case supplier's revenue is a function of the retailer's ordering decision while retailer's ordering decision is a function of the contract terms. Heese and Kemahlioglu-Ziya (2014) address this problem from a supply chain perspective. However, they also consider demand distribution to be a common knowledge for the players.

Extensive empirical works have been reported in the literature on behavioural cheating. Impact of various factors have been studied, viz. monitoring (Fischbacher and Follmi-Heusi, 2013; Schweitzer et al., 2016, etc.); incentives (Mazar et al., 2008; Gill et al., 2013, etc.). However, no experimental study could be identified on this problem in the context of a retail supply chain which differs from the aforesaid situations where the supplier must decide her action ex ante the realization of market demand.

In this study, we consider both the approaches mentioned above. Towards the first approach of eliciting true information from the retailer, we design a menu of contracts which is optimal for the supplier. An "optimal" contract is the one which gives maximum expected profit to a supplier given that the retailer gets his reservation profit. Here, the reservation profit is the lowest profit at which the retailer accepts a contract. Unlike the models available in literature, we assume that the retailer and the supplier have different beliefs about the demand distribution. For the second approach of preventing the retailer from under-reporting, we perform a randomized controlled experiment to investigate how the audit decision is influenced by retailer's decisions. Building on findings from it we performed a simulation experiment to investigate different parameters which should be considered by a supplier in designing an audit-based contract to obtain maximum payoff.

This paper has been organized as follows: in the next section, we design a menu of contracts for the suppliers under a two-part demand distribution. In Section 3 we report our controlled experiment while Section 4 describes our simulation experiment. Section 5 concludes and summarizes our findings. 
International Journal of Mathematical, Engineering and Management Sciences

Vol. 5, No. 5, 820-834, 2020

https://doi.org/10.33889/IJMEMS.2020.5.5.064

\section{Contract to Elicit Truthful Information from the Retailer}

The supply chain under the consideration comprises of one retailer and one supplier. The supplier produces a product at a unit cost $c$, gives it to the retailer at unit wholesale price $w$. The retailer sells the product in open market at a retail unit price $r$. For every unit of product sold, the contract stipulates a transfer of $\alpha$ fraction of the sales revenue, $r$. Salvage value of unsold quantity and goodwill cost of unmet demand is assumed to be zero. The market can assume two states: low $(L)$ and high $(H)$. Demand follows pdf $f_{L}(x)$ and $f_{\mathrm{H}}(x)$ in low and high states respectively such that $F_{H}(x)>F_{L}(x), \forall \mathrm{x} \geq 0$ where $F_{i}(x), \mathrm{i}=H, L$ denotes the cdf of demand. The retailer knows for sure which demand state the market will assume - even though he doesn't know the exact demand till it is realized. Hence, we designate a retailer corresponding to a market state $i(i=H, L)$, to be of retailer type $(i)$. On the other hand, the supplier only has a subjective assessment $p$ for the low demand state, and this is her private information. In order to know the retailer type, she offers a menu of contracts $\left(w_{j}, \alpha_{j}, T_{j}\right)$ where $j$ also takes value in $\{H, L\}$ corresponding to the supplier's belief about the market state, so that the selection of the contract by a retailer reveals his type and in turn the market state. Here $T_{j}(\mathrm{j}=H, L)$ are fixed fees the retailer needs to pay at the beginning. This may be assumed as franchisee fee. We designate a contract $\left(w_{j}, \alpha_{j}, T_{j}\right)$ as contract type $j$ where $j=H, L$. The supplier needs to decide the contract parameters viz. $w_{j}, \alpha_{j}, T_{j}$ such that a retailer type $L(H)$ does not have any incentive to choose a contract type $H(L)$ and at the same time maximizes her expected profit. However, there might be a deviation from this since a supplier might not know the retailer's reservation profit. Thus, if a retailer type $i$ chooses contract type $j$, his profit as a function of the menu is given by Eq. (1):

$$
\begin{array}{r}
\pi_{i}^{R}\left(w_{j}, \alpha_{j}, T_{j}, Q\right)=-w_{j} \mathrm{Q}+\mathrm{r}\left(1-\alpha_{j}\right) \mathrm{E}\{\min (D, Q)\}-T_{j} \\
=-w_{j} \mathrm{Q}+\mathrm{r}\left(1-\alpha_{j}\right) \int_{0}^{Q} \bar{F}_{l}(x) d x-T_{j}
\end{array}
$$

where, $\bar{F}_{l}(x)=1-F_{i}(x)$ and, $\min (D, Q)=\int_{0}^{Q} x f(x) d x+\int_{Q}^{\infty} Q f(x) d x$.

We arrived at Eq. (1) using the Expectation theorem, $\int_{0}^{y} x f(x) d x=y \mathrm{~F}(y)-\int_{0}^{y} F(x) d x$.

The decision of the supplier needs to be set such that the retailer orders optimally. The optimal quantity $\left(Q_{i j}\right)$ of a retailer type $i$ if he chooses contract type $j$ is

$Q_{i j}=\underset{Q}{\operatorname{argmax}} \pi_{i}^{R}\left(w_{j}, \alpha_{j}, T_{j}, Q\right) \Rightarrow\left(1-\alpha_{j}\right) \mathrm{r} \bar{F}_{l}\left(Q_{i j}\right)=w_{j}$

Substituting Eq. (2) in Eq. (1)

$$
\pi_{\mathrm{i}}^{\mathrm{R}}\left(w_{j}, \alpha_{j}, T_{j}, Q_{i j}\right)=\mathrm{r}\left(1-\alpha_{j}\right) \int_{0}^{Q_{i j}} x f_{i}(x) d x-T_{j}
$$

Supplier's profit,

$$
\begin{aligned}
\pi_{i}^{s}\left(w_{j}, \alpha_{j}, T_{j}\right)= & \left(w_{j}-c\right) Q_{i j}+\operatorname{r\alpha } \alpha_{j} \min \left\{Q_{i j}, \mathrm{D}\right\}+T_{j} \\
& =\left(w_{j}-c\right) Q_{i j}+\mathrm{r} \alpha_{j} \int_{0}^{Q i j} \overline{F_{l}}(x) \mathrm{dx}+T_{j}
\end{aligned}
$$


Now, the problem of the supplier is to maximize her expected profit subjected to the individual rationality (IR) and the incentive compatibility (IC) constraint of the retailer. The supplier's problem, given the retailer's reservation value $(\rho)$, is represented as follows:

$$
\begin{aligned}
& \max _{\mathrm{w}_{\mathrm{L}}, \alpha_{\mathrm{L}}, \mathrm{T}_{\mathrm{L}}, \mathrm{w}_{\mathrm{H}}, \alpha_{\mathrm{H}}, \mathrm{T}_{\mathrm{H}}} \pi^{\mathrm{S}=} \mathrm{p} \pi_{L}^{S}\left(w_{L}, \alpha_{L}, T_{L}\right)+(1-p) \pi_{H}^{S}\left(w_{H}, \alpha_{H}, T_{H}\right) \\
& \text { s.t. } \quad \\
& \qquad \begin{aligned}
&{ }_{L}^{R}\left(w_{L}, \alpha_{L}, T_{L}, Q_{L L}\right) \geq \rho \\
& \pi_{H}^{R}\left(w_{H}, \alpha_{H}, T_{H}, Q_{H H}\right) \geq \rho \\
& \pi_{L}^{R}\left(w_{L}, \alpha_{L}, T_{L}, Q_{L L}\right) \geq \pi_{L}^{R}\left(w_{H}, \alpha_{H}, T_{H}, Q_{L H}\right) \\
& \pi_{H}^{R}\left(w_{H}, \alpha_{H}, T_{H}, Q_{H H}\right) \geq \pi_{H}^{R}\left(w_{L}, \alpha_{L}, T_{L}, Q_{H L}\right)
\end{aligned}
\end{aligned}
$$

From Eq. (2), we have:

$\mathrm{Q}_{\mathrm{HL}}=\mathrm{F}_{\mathrm{H}}^{-1}\left[\mathrm{~F}_{\mathrm{L}}\left(\mathrm{Q}_{\mathrm{LL}}\right)\right] \Rightarrow \frac{\partial Q_{H L}}{\partial Q_{L L}}=\frac{f_{L}\left(Q_{L L}\right)}{f_{H}\left(Q_{H L}\right)}$

The supplier will get higher wholesale revenue if the retailer orders higher quantity even in the low demand state. On the contrary, if the retailer orders low quantity even in higher market state, it is not beneficial for both the parties. Hence, Eq. (IC-1) should be binding in the optimal condition; Also, in the optimal condition Eq. (IR-1) should be binding, otherwise by adjusting $T_{L}$ the supplier can do this. Moreover, Eq. (IR-1) and Eq. (IC-2) imply Eq. (IR-2), hence is redundant. Thus, the supplier's problem reduces to Eq. (5), subject to Eq. (IR-1), Eq. (IC-1) and Eq. (IC-2). From Eq. (IR-1) and Eq. (IC-1) respectively, we have

$$
\begin{aligned}
& \pi_{\mathrm{L}}^{\mathrm{R}}\left(\mathrm{w}_{\mathrm{L}}, \alpha_{\mathrm{L}}, \mathrm{T}_{\mathrm{L}}, \mathrm{Q}_{\mathrm{LL}}\right)=\rho \Rightarrow \mathrm{T}_{\mathrm{L}}=\left(1-\alpha_{\mathrm{L}}\right) \mathrm{r} \int_{0}^{\mathrm{Q}_{\mathrm{LL}}} \mathrm{xf}_{\mathrm{L}}(\mathrm{x}) \mathrm{dx}-\rho \\
& \pi_{L}^{R}\left(w_{L}, \alpha_{L}, T_{L}, Q_{L L}\right)=\pi_{L}^{R}\left(w_{H}, \alpha_{H}, T_{H}, Q_{L H}\right) \\
& \Rightarrow T_{H}=\left(1-\alpha_{H}\right) \mathrm{r} \int_{0}^{Q_{L H}} x f_{L}(x) d x-\rho
\end{aligned}
$$

Substituting the values from Eq. (2), Eq. (4), Eq. (7) and Eq. (8) in Eq. (5), the supplier's expected profit is:

$$
\begin{aligned}
\pi^{S}=p[(r-c) & \left.Q_{L L}-r\left\{Q_{L L} F_{L}\left(Q_{L L}\right)-\int_{0}^{Q_{L L}} x f_{L}(x) d x\right\}\right] \\
& +(1-p)\left[\left\{\left(1-\alpha_{H}\right) r-c\right\} Q_{H H}-\left(1-\alpha_{H}\right) r\left\{Q_{H H} F_{H}\left(Q_{H H}\right)\right.\right. \\
& \left.\left.-\int_{0}^{Q_{L H}} x_{L}(x) d x\right\}+\alpha_{H} r \int_{0}^{Q_{H H}} \overline{F_{H}}(x) d x\right]-\rho
\end{aligned}
$$


The first-order derivatives of Eq. (9) are,

$$
\begin{aligned}
& \frac{\partial \pi^{S}}{\partial \alpha_{L}}=0 \\
& \frac{\partial \pi^{S}}{\partial \alpha_{H}}=r(1-p)\left[\int_{0}^{Q_{H H}} x_{H}(x) d x-\int_{0}^{Q_{L H}} x_{L}(x) d x\right] \leq 0 \text { (proof in Appendix A.1) } \\
& \frac{\partial \pi^{S}}{\partial Q_{L L}}=\mathrm{p}\left[(r-c)-r\left\{\frac{\partial}{\partial Q_{L L}} Q_{L L} F_{L} Q_{L L}-\frac{\partial}{\partial Q_{L L}} \int_{0}^{Q_{L L}} x f_{L}(x) d x\right\}\right] \\
& +(1-p)\left[-\frac{\partial}{\partial Q_{L L}} \int_{0}^{Q_{L H}} x f_{L}(x) d x\right] \\
& =\mathrm{p}\left[(\mathrm{r}-\mathrm{c})-\mathrm{rF}_{\mathrm{L}}\left(\mathrm{Q}_{\mathrm{LL}}\right)\right] \\
& \frac{\partial \pi^{S}}{\partial Q_{H H}} \quad=(1-p)\left[\left(1-\alpha_{H}\right) \mathrm{r}-\mathrm{c}-\left(1-\alpha_{H}\right) \mathrm{r}\left\{\frac{\partial}{\partial Q_{H H}} Q_{H H} F_{H}\left(Q_{H H}\right)\right.\right. \\
& \left.\left.-\frac{\partial}{\partial Q_{H H}} \int_{0}^{Q_{\mathrm{LH}}} \mathrm{xf}_{\mathrm{L}}(\mathrm{x}) \mathrm{dx}\right\}+\mathrm{r} \alpha_{\mathrm{H}} \frac{\partial}{\partial Q_{H H}} \int_{0}^{Q_{H H}} \overline{F_{H}}(x) d x\right]
\end{aligned}
$$

Substituting from Eq: (6)

$$
\frac{\partial \pi^{S}}{\partial Q_{H H}}=(r-c)-\mathrm{r} F_{H}\left(Q_{H H}\right)-\mathrm{r}\left(1-\alpha_{H}\right) Q_{H H} f_{H}\left(Q_{H H}\right)
$$

For first order necessary condition of optimality, we equate Eq. (10), Eq. (11), Eq. (12), and Eq. (13) to zero. We have the following optimal solution.

$$
\begin{aligned}
& \alpha_{L}^{*} \ldots \text { Not unique } \\
& \alpha_{H}^{*} \underline{\alpha} \leq \alpha \leq 1 \\
& Q_{L L}^{*}=F_{L}^{-1}\left(\frac{r-c}{r}\right) \\
& F_{H}\left(Q_{H H}^{*}\right)+\left(1-\alpha_{H}^{*}\right) Q_{H H}^{*} f_{H}\left(Q_{H H}^{*}\right)=\frac{\mathrm{r}-\mathrm{c}}{\mathrm{r}}
\end{aligned}
$$

In Eq. (15) $\underline{\alpha}$ is any value of revenue transfer fraction less than $\alpha$ which might be acceptable to the supplier. The optimal value of the other parameters can be calculated by substituting the above values in Eq. (7) and Eq. (8). In case of a coordinated supply chain under a revenue sharing contract, the optimal ordered quantity by a retailer satisfies the condition $F(Q)=\frac{r-c}{r}$ where the supplier's decision satisfies the relation $w=(1-\alpha) c$ (Cachon and Lariviere, 2005). From Eq. (16), Eq. (17) it is seen that $Q_{L L}^{*}$ satisfies the coordinating condition while $Q_{H H}^{*}$ does so only if $\alpha \rightarrow 0$. This implies that the supplier should extract all the sales revenue from the retailer which is practically infeasible. Thus, the above menu of contracts coordinates the supply chain only under low demand scenario. 
International Journal of Mathematical, Engineering and Management Sciences

Vol. 5, No. 5, 820-834, 2020

https://doi.org/10.33889/IJMEMS.2020.5.5.064

Since eliciting true information from the retailer works in a limited sense, we turn our attention to the second approach. We now analyze an audit-based contract.

\section{Effect of an Audit in a Revenue Sharing Contract: Experimental Study}

An implicit assumption in the classical revenue sharing contract (Cachon and Lariviere, 2005) is that the retailer always reports the actual revenue. However, to achieve contract compliance in practice, firms need to resort to auditing. As discussed earlier, auditing is predominant in the tax evasion scenario (Townsend, 1979; Sandmo, 2005 etc.). In this section, we investigate how the audit decision of a supplier is influenced by any mismatch between the retailer's ordered quantity and the reported sales figure. We define Suspect-ratio as:

$$
\text { Suspect-ratio }=\frac{\text { Ordered quantity }- \text { Reported quantity }}{\text { Ordered quantity }} .
$$

Intuition is that, with the increase in Suspect-ratio, a supplier should be more vigilant resulting in an increased audit probability. Therefore, we posit that

Hypothesis: Supplier's audit probability increases with the Suspect-ratio.

We conduct laboratory experiment to investigate our hypothesis in a two-stage supply chain where the market demand is visible only to the retailer.

\subsection{Experimental Procedure}

Several teams of two students were created. In each team, one member played the role of a retailer, while the other a supplier. Our experiment was in the form of an online game. We recruited 144 students from a premier technological university in India. Formation of teams and assignment of roles to the team members were done randomly. Team members were kept anonymous of each other. We controlled the market demand.

At the beginning of the game, instructions were displayed at the game terminals. Manipulation check was done and only those who passed it proceeded to the game. Everyone was provided with two years of historical demand information. Market demand followed Unif [50, 100] and this was common information. However, the exact realization of demand in a month was only visible to the retailer. The supplier's only source of knowledge is a sales report submitted by the retailer at the end of the month.

At the beginning of a month (a month corresponds to a round in the game), both the players in a team were required to forecast demand for that month independently based on the two years history provided. The supplier was provided with the history of sales report while the retailer with the demand realization. Thereafter, the participant who plays the role of the retailer placed order $(Q)$, the participant who plays the role of the supplier is supposed to have produced those at a unit cost (c) INR 20, and sold to the retailer at a unit wholesale price (w) INR 30. Subsequently, market demand $(D)$ was revealed. Retailer met the market demand $(\min \{D, Q\})$ at unit retail price $(\mathrm{r})$ of INR 100 . For every unit sold in the market, he shares $(\alpha) 25 \%$ of the sales revenue. Thereafter, the retailer decided the quantity to be reported $(\mathrm{R})$ which appeared on the supplier's terminal and revenue share (fraction of the reported sales) was added to her account from the retailer's. The supplier could call for an audit if she wanted to verify the reported sales, by paying a fee $\left(C_{a}\right)$ INR 100. The retailer was notified (through the game) of the supplier's audit decision and the retailer 
International Journal of Mathematical, Engineering and Management Sciences

Vol. 5, No. 5, 820-834, 2020

https://doi.org/10.33889/IJMEMS.2020.5.5.064

had under-reported the sales, the unreported revenue share along with a penalty $(T)$ of INR 150 was deducted from his account and was added to the supplier's if an audit was called. Payoffs for the supplier $\left(\pi^{S}\right)$ and the retailer $\left(\pi^{R}\right)$ appeared on their respective screens which were calculated as:

$$
\begin{aligned}
& \pi^{\mathrm{S}}=-c Q+\mathrm{wQ}+\alpha \mathrm{rR}+\gamma_{\mathrm{S}}\left[\delta_{R}\{\alpha \mathrm{r}(\mathrm{A}-\mathrm{R})+\mathrm{T}\}-\mathrm{C}_{\mathrm{a}}\right] \\
& \pi^{R}=-\mathrm{wQ}+\mathrm{rA}-\alpha \mathrm{rR}-\gamma_{\mathrm{S}} \delta_{\mathrm{R}} \mathrm{T}
\end{aligned}
$$

Here, $A$ is the actual sales, $\gamma_{S}$ takes value $l$ if the supplier decided to call an audit, and 0 otherwise while $\delta_{R}$ becomes 1 if the retailer cheated in that month, and 0 otherwise.

The game was stopped in an arbitrary month for different teams. But they played for a minimum of seven months. We calculated the Suspect Ratio of each month for each supplier and the number of times they called audit in the game horizon.

\subsection{Results}

Suspect ratio is on a continuous scale in $[0,1]$. We divide this range in four equal buckets each of length 0.25 . The buckets are labelled as B1 (0-0.25), B2 (0.25-0.5), B3 (0.5-0.75) and B4 (0.751.0). There the numbers in the brackets indicate the range of values for the suspect ratio. We count the number of times each supplier called for an audit in the game horizon and calculated the average count by diving it by the length of the game horizon (which was 7). These are termed as Normalized Audit Count (NAC). We performed one-way ANOVA test among these buckets of Suspect Ratio with average number of audits per month as the dependent variable.

Table 1. Games-Howell multiple comparisons

\begin{tabular}{|c|c|c|c|c|}
\hline Suspect ratio (A) & Suspect ratio (B) & Mean diff. (A-B) & Std. error & Sig. \\
\hline \multirow{3}{*}{ B1 } & B2 & -0.002 & 0.002 & 0.801 \\
\cline { 2 - 5 } & B3 & $-0.013^{*}$ & 0.003 & 0.001 \\
\cline { 2 - 5 } & B4 & $-0.023^{*}$ & 0.003 & 0.000 \\
\hline \multirow{3}{*}{ B2 } & B1 & 0.002 & 0.002 & 0.801 \\
\cline { 2 - 5 } & B3 & $-0.010^{*}$ & 0.003 & 0.004 \\
\cline { 2 - 5 } & B4 & $-0.021^{*}$ & 0.003 & 0.000 \\
\hline \multirow{3}{*}{ B3 } & B1 & $0.013^{*}$ & 0.003 & 0.001 \\
\cline { 2 - 5 } & B2 & $-0.011^{*}$ & 0.003 & 0.004 \\
\cline { 2 - 5 } & B4 & $0.023^{*}$ & 0.004 & 0.086 \\
\hline \multirow{3}{*}{ B4 } & B1 & $0.021^{*}$ & 0.003 & 0.000 \\
& B2 & 0.010 & 0.003 & 0.000 \\
\cline { 2 - 5 } & B3 & & & 0.086 \\
\hline
\end{tabular}

The homogeneity assumption was not satisfied (Levene test turned out to significant). Hence, we performed Welch's ANOVA (Welch, 1951) followed by Games-Howell post-hoc test (Games and Howell, 1976). ANOVA turned out to be significant $\left(F_{(3,112,0.05)}=19.903, p=.000\right)$. This implies that the mean suspect ratios are significantly different across the buckets. The results of post-hoc test are shown in Table 1. From mean differences between the buckets, it is evident that the average number of audit increases from bucket B1 to B4. However, there is no significant increase from B1 to B2 and B3 to B4. This supported our hypothesis that supplier's audit probability increases with Suspect Ratio. Intuitively, a retailer should order less if he forecasts low demand in the market. Hence, greater the difference between ordered quantity and reported 
International Journal of Mathematical, Engineering and Management Sciences

Vol. 5, No. 5, 820-834, 2020

https://doi.org/10.33889/IJMEMS.2020.5.5.064

quantity, higher should be the supplier's suspicion and hence increased audit probability.

The mean normalized audit count (MNAC) of the respective Suspect Ratio buckets are plotted in Figure 1. It shows a linear trend of the MNACs across the Suspect Ratio buckets.

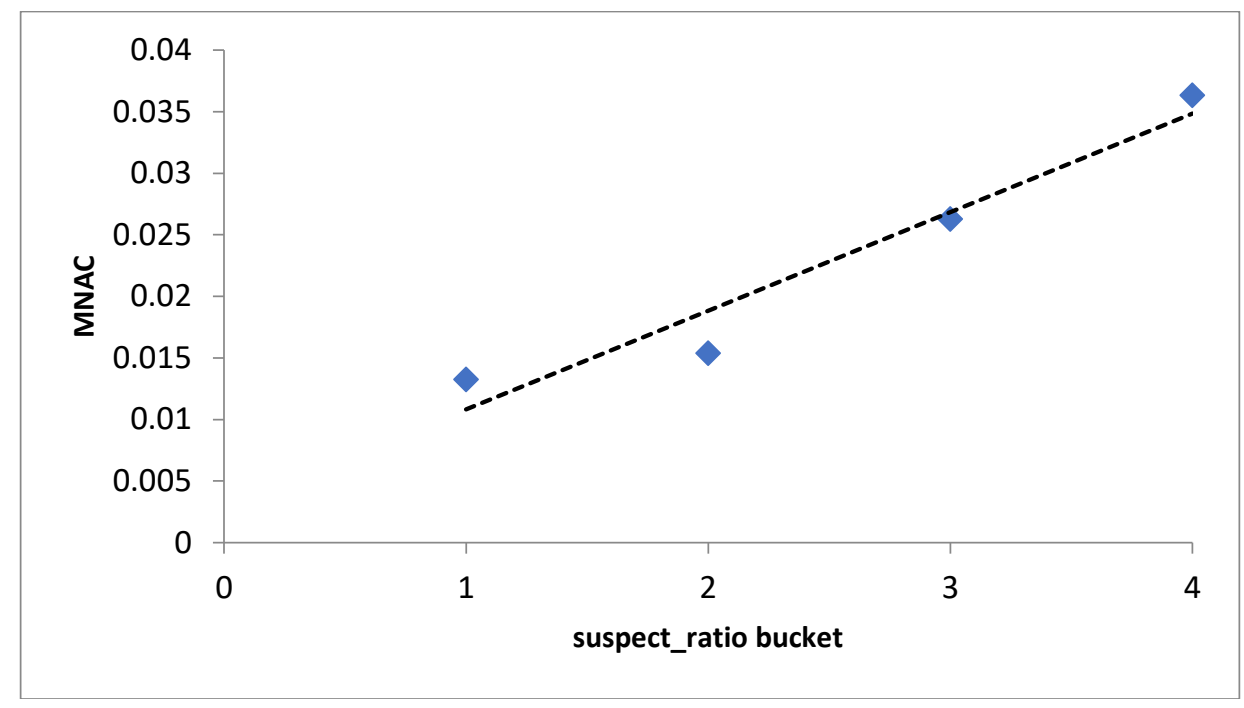

Figure 1. Trend of mean normalized audit count (MNAC) across the suspect ratio buckets

\section{Simulation Study}

In practice, a supplier conducts audit to check the authenticity of the information provided by the retailer by comparing the retailer's sales reports and the order quantities. But invoking an audit every time she suspects the sales could typically be costly and cumbersome. This brings in the possibility of a probabilistic audit where the supplier audits a random sample of sales reports rather than each one. The experiment also proved that the supplier doesn't call for an audit frequently (hence the normalized audit count value in the Figure 1 is quite low). In this section we find out a few factors which help devise strategy for the supplier in deciding on the audit probability.

We assume that the supplier has contract history with the retailer. This history brings the following details: (i) the retailer's order quantity, (ii) the sales reported by him, (iii) the supplier's audit decisions and (iv) whether the retailer cheated or not (known only when an audit was conducted). Our objective is to develop a simulation model to decide on the parameters of an optimal audit policy that maximizes supplier's expected profit in such a scenario.

Players in our model have their own demand forecast which may not be the same. This is because retailer's actual sales history might differ from what he reports to the supplier. We further assume that the retailer does not cheat during the period of low market demands (since that is not rational for the retailer). Both the parties are assumed to maximize their individual utilities. The sequence of events is shown in Figure 2. 
International Journal of Mathematical, Engineering and Management Sciences

Vol. 5, No. 5, 820-834, 2020

https://doi.org/10.33889/IJMEMS.2020.5.5.064

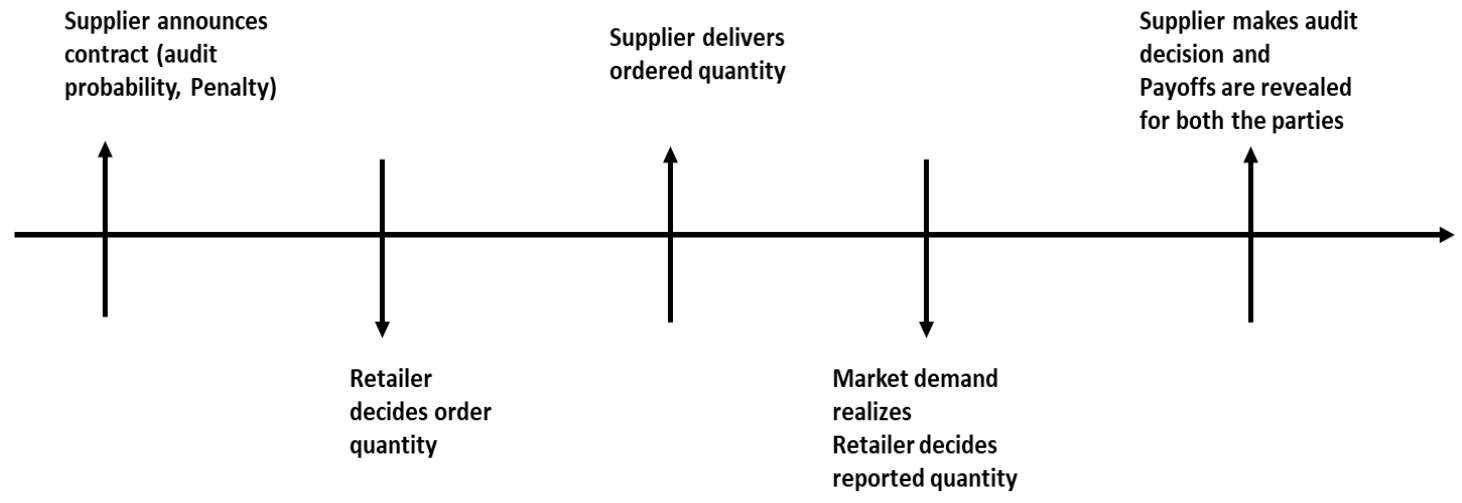

Figure 2. The timeline of events

We use similar notations for the parameters as defined in Section 3.1. The supplier divides the range of reported sales quantity into two buckets: low demand, $\mathrm{Q}_{\mathrm{L}} \in[\mathrm{a}, \mathrm{b}]$ and high demand, $Q_{H} \in$ $(b, c]$. Respective probability density functions (pdf) for the market states, $f_{i}(x) ; i=\{L=$ low, $H=h i g h\}$ are calculated using historical sales report. Similar to what we assume in Section 2 , the supplier has subjective probability $p$ with which she believes that the market will assume low demand state. Payoffs of the supplier $\left(\pi^{S}\right)$ and the retailer $\left(\pi^{R}\right)$ are:

$$
\begin{aligned}
& \pi^{S}=-\mathrm{cQ}+\mathrm{wQ}+\alpha \mathrm{rR}+\mathrm{P}(Q, R)\left\{\delta_{R} \mathrm{~T}\left(A^{\prime}, R\right)-C_{a}\right\} \\
& \pi^{\mathrm{R}}=-\mathrm{wQ}+\mathrm{rA}+[\mathrm{Q}-\mathrm{D}]^{+} \mathrm{s}-[D-Q]^{+} \mathrm{g}-\alpha r R-\mathrm{P}(Q, R) \delta_{R} \mathrm{~T}(A, R)
\end{aligned}
$$

Where, $s$ and $g$ respectively denote the salvage revenue for an unsold unit and good-will loss of an unmet market demand at the month end; $P(Q, R), T(A, R)$ denote respectively the probability of audit and the penalty imposed on the retailer if his cheating is caught during an audit. The supplier's expected actual sales $\left(A^{\prime}\right)$ calculated on the history of sales report she possesses is given by $A^{\prime}=$ $p Q_{L}+(1-p) Q_{H}$. Our experiment in Section 3 infers that the audit probability has linear trend with Suspect Ratio. Hence, we define $P(Q, R)=\gamma\left(\frac{Q-R}{Q}\right)$ where $\gamma$ is the weight which measures how much importance the supplier attaches to a mismatch between $Q$ and $R$. This can assume any positive value. A higher value of this weight implies a highly suspicious supplier. Since this also implies a high audit probability, this increases the audit cost of the supplier. We assume that the supplier would not audit when $Q \in Q_{L}$ since expected recovery is low compared to the audit cost whereas she will always audit if $Q \in Q_{H}$ and $R<A^{\prime}$ since this is an indicator of under-reporting by the retailer. If $Q \in Q_{H}$ and $R \geq A^{\prime}$ she has to decide $P(Q, R)$. We further assume the penalty function to be $T(A, R)=\theta(A-R) r$ for our simulation, where $\theta>0$ is the penalty factor. We restrict $\theta \leq 3$ since larger penalty may not be enforceable due to the prevailing laws.

\subsection{Simulation Algorithm}

A Monte Carlo (MC) algorithm has been developed using Python language. We design two classes for our algorithm viz. History and Game. History generates the contract history for $n$ number of periods which includes the fields: (i) actual market demand $(A)$, (ii) reported demand $(R)$, (iii) whether audit was called or not and, (iv) the supplier's expected market demand $\left(A^{\prime}\right)$. Game develops the game between the players by (i) generating the penalty $(T(A, R))$ and the audit 
International Journal of Mathematical, Engineering and Management Sciences

Vol. 5, No. 5, 820-834, 2020

https://doi.org/10.33889/IJMEMS.2020.5.5.064

probability $(P(Q, R))$, (ii) generating the retailer's order quantity $(Q)$ and reported quantity $(\mathrm{R})$, (iii) providing the supplier's decision to audit or not.

\subsection{Performance Measures}

We have three performance measures: (i) the Supplier's profit improvement factor (SPIF) which is defined as the ratio of her post-audit profit to pre-audit profit. A non-negative SPIF implies the audit is a success i.e. audit has been called appropriately. (ii) the Retailer's failure ratio (RFR) which is the ratio of the number of times he is caught cheating because of audit to the number of times he has cheated the supplier. If a retailer cheats in a month but he has not faced an audit, this is a success to him. (iii) the Supplier's success ratio (SSR) which is defined as the proportion of times a retailer is caught cheating when an audit is conducted to the number of times the supplier calls for audit. That way, as the aim of audit is to catch the cheating retailer, it can be called as supplier's success. Supplier's decision in the game is assessed and analyzed with these performance measures by varying the parameters viz. penalty factor $(\theta)$, suspicion weight $(\gamma)$ and, audit cost $\left(C_{a}\right)$.

\subsection{Results}

All the analysis in this section is carried out with 10,000 replications, for at this level the Monte Carlo (MC) simulation error is very close to zero (0.01, 0.02 and 0.01 for SPIF, SSR and RFR respectively). The parameter values we considered are $c=20, w=30, r=100, \alpha=0.2, s=0, g=$ $0, C_{a}=150, \theta=2$.

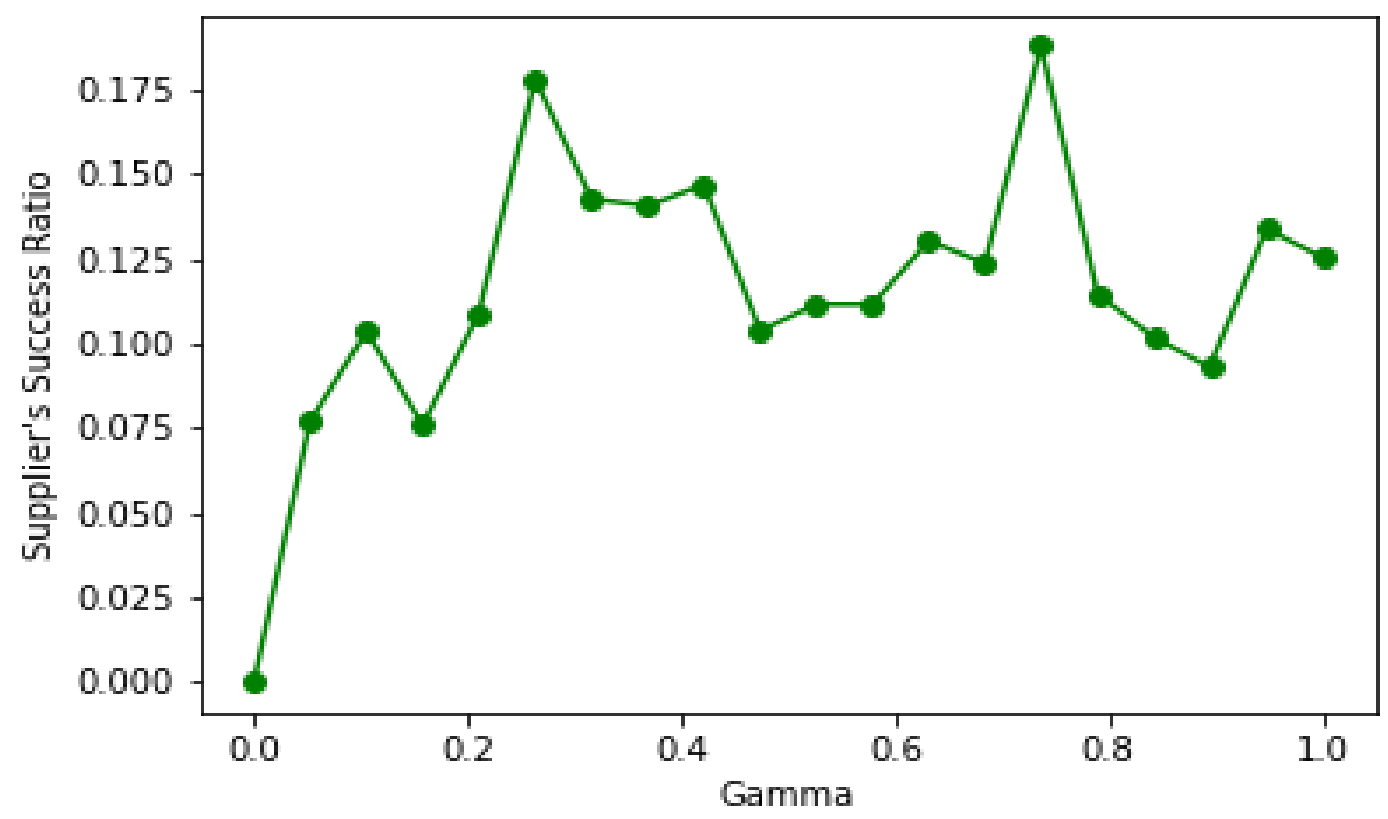

Figure 3. Effect of suspicion weight $(\gamma)$ on supplier's success ratio 
International Journal of Mathematical, Engineering and Management Sciences

Vol. 5, No. 5, 820-834, 2020

https://doi.org/10.33889/IJMEMS.2020.5.5.064

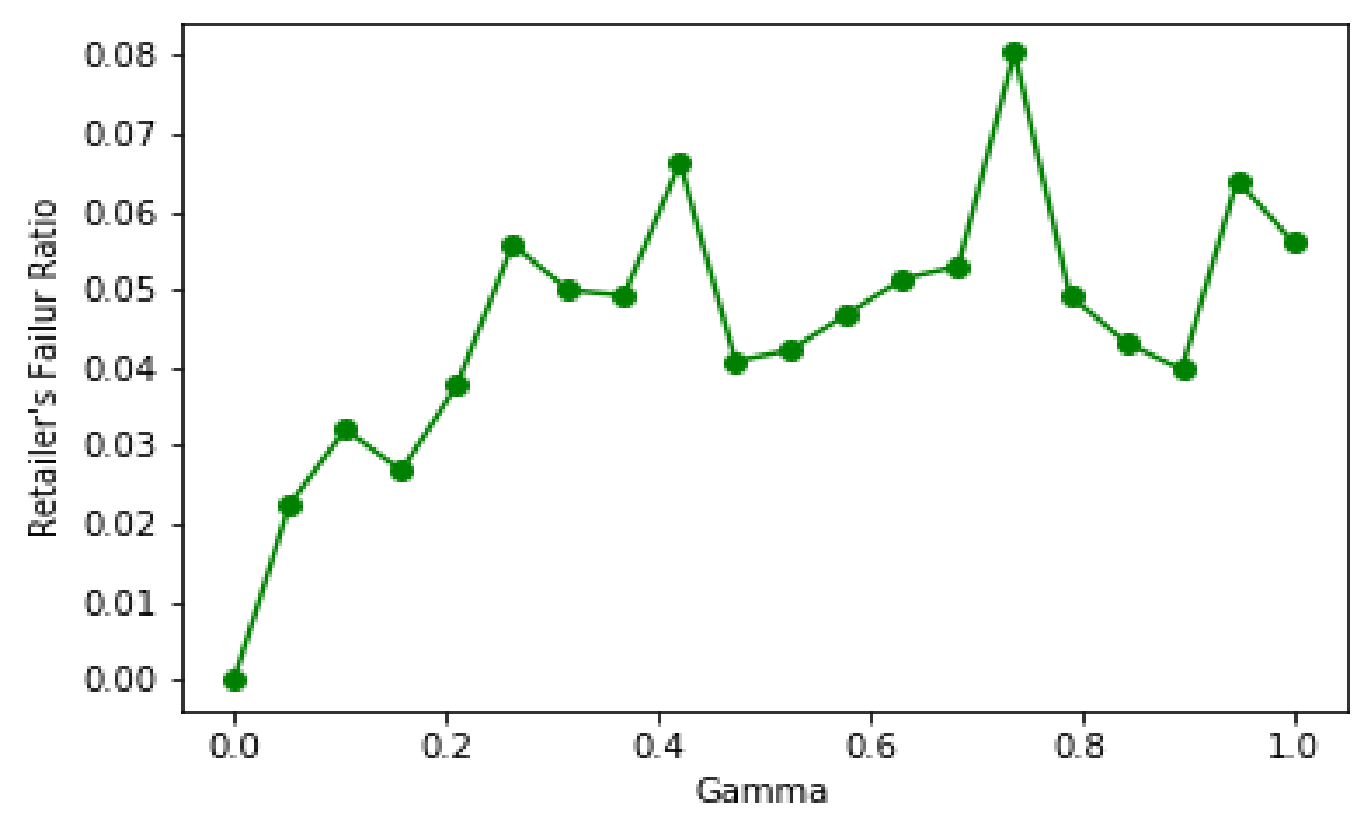

Figure 4. Effect of suspicion weight $(\gamma)$ on retailer's failure ratio

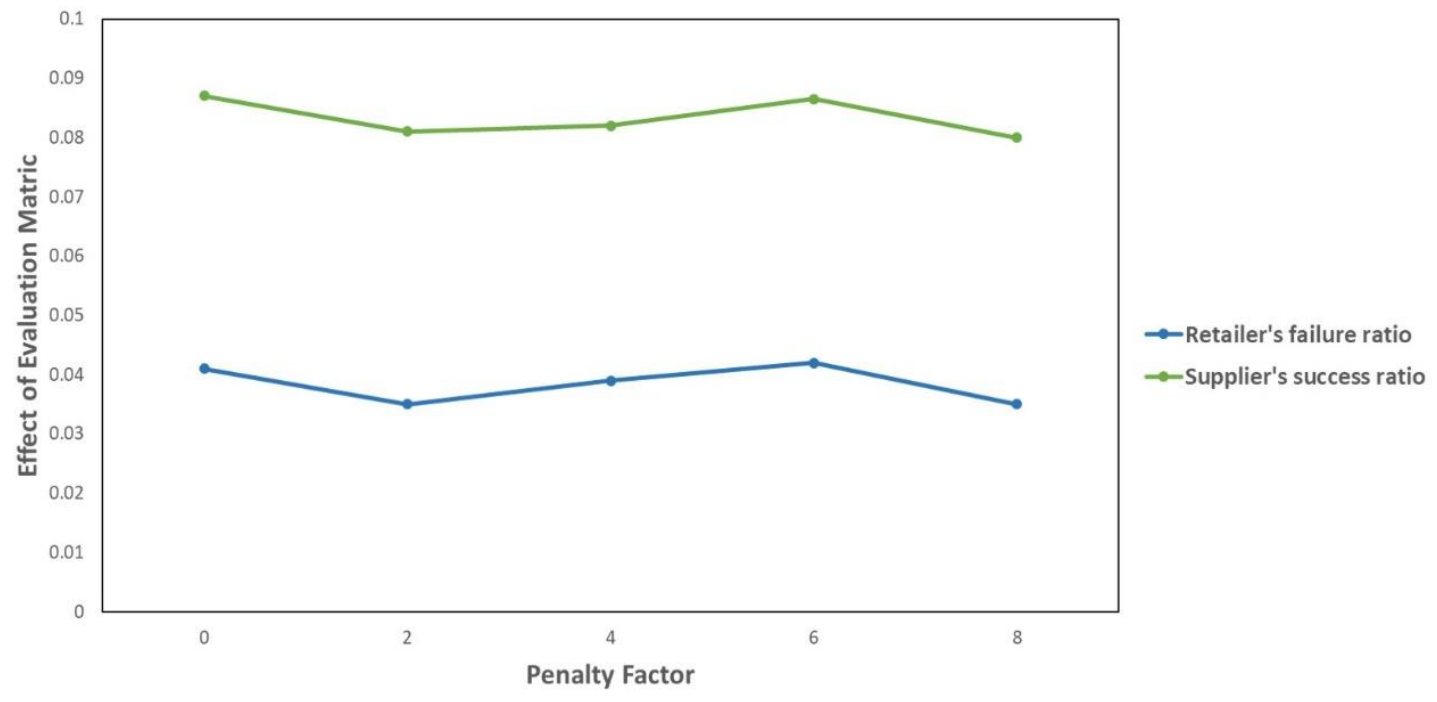

Figure 5. Effect of the penalty factor $(\theta)$ SSR and RFR

From Figure 3 and Figure 4 we can infer that with the increase in suspicion weight $(\gamma)$, both SSR (Figure 3) and RFR (Figure 4) increase. However, the SPIF decreases with increase in cost of audit (Figure 6). Cost of audit is a function of suspicion weight $(\gamma)$. This weight should be decided such that the expected recovery from auditing is greater than the cost incurred in the audit process. Beyond a threshold audit cost (Rs. 1000), auditing is not economically viable as SPIF falls below $l$ which means that the supplier earns less by auditing. In reality, the audit cost is determined by 
International Journal of Mathematical, Engineering and Management Sciences

Vol. 5, No. 5, 820-834, 2020

https://doi.org/10.33889/IJMEMS.2020.5.5.064

the market. Thus, the supplier must make the decision to audit based on the estimated audit cost.

From Figure 5 it is evident that the effect of the penalty factor $(\theta)$ has similar trend on both SSR and RFR. Since, the penalty factor $(\theta)$ is a hyper- parameter chosen by the supplier, she could choose the one that provides her the highest utility taking to consideration the retailer's reservation profit in her calculations.

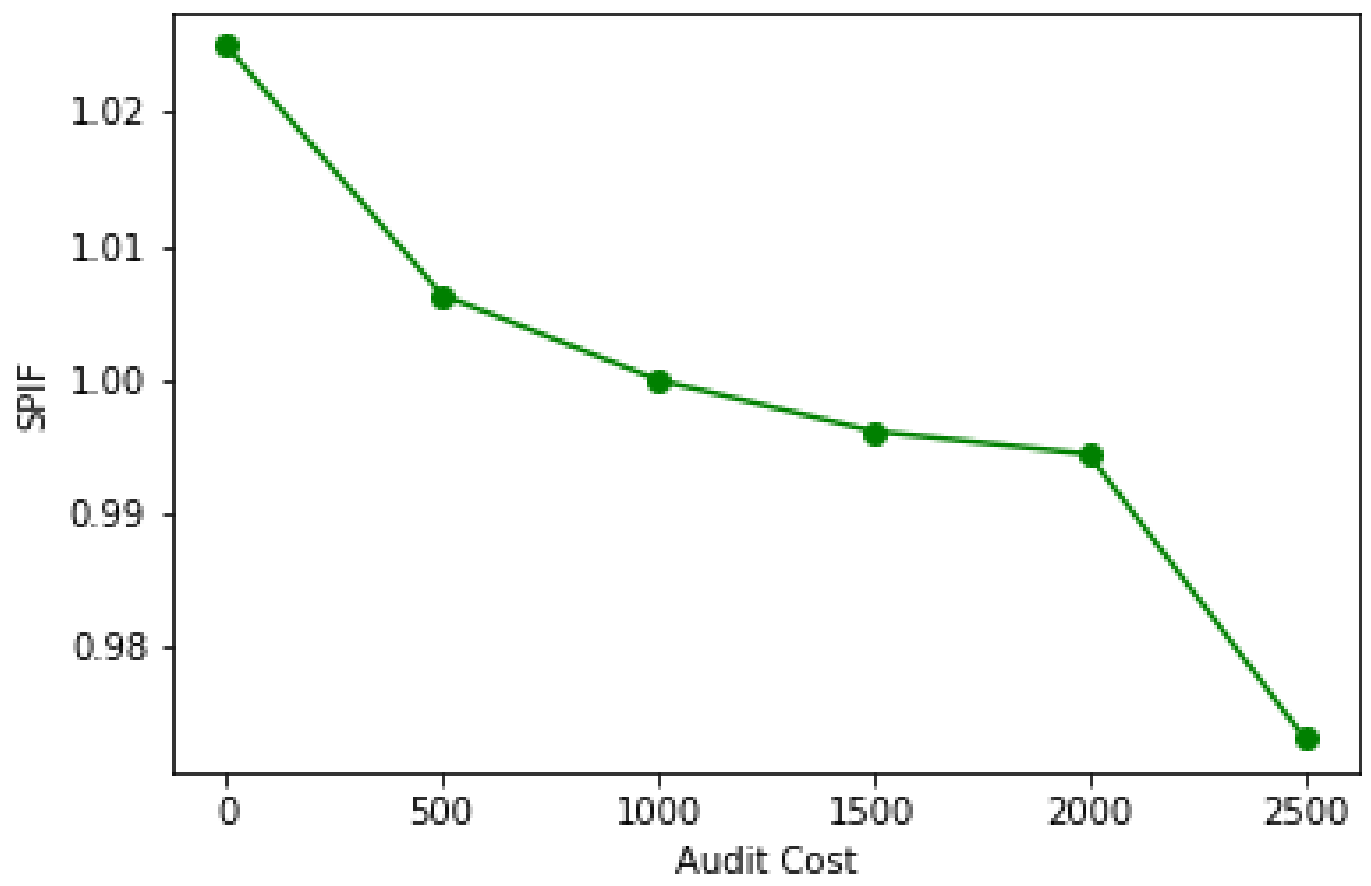

Figure 6. Effect of audit cost on SPIF

\section{Conclusion}

When information is equally available to all the parties in a supply chain, traditional revenue sharing contract is helpful in coordinating the supply chain. However, when the retailer possesses private information, the supplier should adopt means to counter the problem of revenue underreporting. Our work addresses this problem and it aims at finding strategies for the supplier. We design an optimal menu of contract for the supplier to extract truthful information from the retailer (party having superior information). We model our problem with a two-part demand estimates for the supplier which is different from the retailer's demand estimates unlike the existing models in the literature. However, the menu of contracts cannot coordinate the supply chain in a high demand market state. Therefore, we explore the option of an audit-based revenue sharing contract. We perform a laboratory experiment to study how the supplier's audit decision is influenced by the retailer's decisions. We find that the audit probability chosen by the supplier increases with the retailer's order quantity and the reported sales. From the simulation experiment, it appeared that a retailer cheats frequently when both audit probability and the penalty is low. Moreover, there is a threshold for the audit cost beyond which auditing is not economically profitable to call an audit. 
International Journal of Mathematical, Engineering and Management Sciences

Vol. 5, No. 5, 820-834, 2020

https://doi.org/10.33889/IJMEMS.2020.5.5.064

Our findings are helpful for a manager in the supplying firm to design contract under asymmetric information. The parameters of the menu of contracts proposed by us are easy to calculate. These contracts will help her understand the limitation of a contract mechanism to elicit truthful information. Alternatively, if she wants to adopt an audit process, our findings from the simulation experiment will help him identifying a few factors to make it effective.

Analytical model to design a game with reputation loss of the supplier where she calls an audit even when the retailer reports the truth could be an interesting future direction. Exploring retailer types based on their reaction to an audit in a contract could be another interesting direction for future work.

\section{Conflict of Interest}

The authors declare that there is no conflict of interest for this publication.

\section{Acknowledgment}

We thank Avilasha, Nilanjan, Mahesh, Kathiresan for helping us conducting the experiment. We thank the editor and the anonymous reviewer for their suggestions on the article. This research did not receive any specific grant from funding agencies in the public, commercial, or not-for-profit sectors.

\section{References}

Arya, A., \& Mittendorf, B. (2004). Using return policies to elicit retailer information. RAND Journal of Economics, 35(3), 617-630.

Baron, D.P., \& Besanko, D. (1984). Regulation, asymmetric information, and auditing. RAND Journal of Economics, 15(4), 447-470.

Burnetas, A., Gilbert, S.M., \& Smith, C.E. (2007). Quantity discounts in single-period supply contracts with asymmetric demand information. IIE Transactions, 39(5), 465-479.

Cachon, G.P., \& Lariviere, M.A. (2005). Supply chain coordination with revenue-sharing contracts: strengths and limitations. Management Science, 51(1), 30-44.

Corbett, C.J. (2001). Stochastic inventory systems in a supply chain with asymmetric information: cycle stocks, safety stocks, and consignment stock. Operations Research, 49(4), 487-500.

Corbett, C.J., \& De Groote, X. (2000). A supplier's optimal quantity discount policy under asymmetric information. Management Science, 46(3), 444-450.

Corbett, C.J., Zhou, D., \& Tang, C.S. (2004). Designing supply contracts: contract type and information asymmetry. Management Science, 50(4), 550-559.

Crocker, K.J., \& Slemrod, J. (2005). Corporate tax evasion with agency costs. Journal of Public Economics, 89(9-10), 1593-1610.

Fischbacher, U., \& Föllmi-Heusi, F. (2013). Lies in disguise — an experimental study on cheating. Journal of the European Economic Association, 11(3), 525-547.

Games, P.A., \& Howell, J.F. (1976). Pairwise multiple comparison procedures with unequal n's and/or variances: a Monte Carlo study. Journal of Educational Statistics, 1(2), 113-125.

Gill, D., Prowse, V., \& Vlassopoulos, M. (2013). Cheating in the workplace: an experimental study of the impact of bonuses and productivity. Journal of Economic Behavior \& Organization, 96, 120-134. 
International Journal of Mathematical, Engineering and Management Sciences

Vol. 5, No. 5, 820-834, 2020

https://doi.org/10.33889/IJMEMS.2020.5.5.064

Ha, A.Y. (2001). Supplier-buyer contracting: asymmetric cost information and cutoff level policy for buyer participation. Naval Research Logistics, 48(1), 41-64.

Heese, H.S., \& Kemahlioglu-Ziya, E. (2014). Enabling opportunism: revenue sharing when sales revenues are unobservable. Production and Operations Management, 23(9), 1634-1645.

Kaplow, L., \& Shavell, S. (1994). Optimal law enforcement with self-reporting of behavior. Journal of Political Economy, 102(3), 583-606.

Kofman, F., \& Lawarree, J. (1993). Collusion in hierarchical agency. Econometrica: Journal of the Econometric Society, 61(3), 629-656.

Laffont, J.J., \& Tirole, J. (1986). Using cost observation to regulate firms. Journal of Political Economy, 94(3), 614-641.

Mazar, N., Amir, O., \& Ariely, D. (2008). The dishonesty of honest people: a theory of self-concept maintenance. Journal of Marketing Research, 45(6), 633-644.

Sandmo, A. (2005). The theory of tax evasion: a retrospective view. National Tax Journal, 58, 643-663.

Schweitzer, M.E., Ho, T.H., \& Zhang, X. (2016). How monitoring influences trust: a tale of two faces. Management Science, 64(1), 253-270.

Skinner, J., \& Slemrod, J. (1985). An economic perspective on tax evasion. National Tax Journal, 38(3), 345-353.

Townsend, R.M. (1979). Optimal contracts and competitive markets with costly state verification. Journal of Economic Theory, 21(2), 265-293.

Welch, B.L. (1951). On the comparison of several mean values: an alternative approach. Biometrika, 38(3/4), 330-336.

\section{Appendix}

A1. Proof for Eq. (11)

Let, $K\left(Q_{H H}\right)=\int_{0}^{\mathrm{Q}_{\mathrm{HH}}} \mathrm{xf}_{\mathrm{H}}(\mathrm{x}) \mathrm{dx}-\int_{0}^{\mathrm{Q}_{\mathrm{LH}}} \mathrm{xf}_{\mathrm{L}}(\mathrm{x}) \mathrm{dx}$

$\Rightarrow K^{\prime}\left(Q_{H H}\right)=Q_{H H} f_{H}\left(Q_{H H}\right)-Q_{L H} f_{L}\left(Q_{L H}\right) \frac{\partial Q_{L H}}{\partial Q_{H H}}$

Here, $Q_{L H}=F_{L}^{-1}\left[F_{H}\left(Q_{H H}\right)\right] \Rightarrow \mathrm{F}_{\mathrm{H}}(\mathrm{y})=\mathrm{F}_{\mathrm{L}}(\mathrm{Z}(\mathrm{y}))$ where $\mathrm{y}=\mathrm{Q}_{\mathrm{HH}}$ such that $\mathrm{Z}(\mathrm{y})=$

$\mathrm{Q}_{\mathrm{LH}} \quad \Rightarrow \mathrm{f}_{\mathrm{H}}(\mathrm{y})=\mathrm{f}_{\mathrm{L}}(\mathrm{Z}(\mathrm{y})) \cdot \mathrm{Z}^{\prime}(\mathrm{y})$

Then, Eq. (A1.1) becomes, $K^{\prime}\left(Q_{H H}\right)=\mathrm{y} f_{H}(y)-\mathrm{Z}(y) f_{L}(Z(y)) Z^{\prime}(y)$

$$
=y f_{L}(Z(y)) \cdot Z^{\prime}(y)-z(y) f_{L}(Z(y)) Z^{\prime}(y)
$$

$=f_{L}(Z(y)) \cdot Z^{\prime}(y)[y-Z(y)]$

$Z(y) \geq y$ since $F_{H}($.$) is non-decreasing. Thus Eq. (A1.2) results that K^{\prime}\left(Q_{H H}\right) \leq 0$ This follows Eq. (11).

\section{A2. Proof for Eq. (9)}

Eq. (5) is 
International Journal of Mathematical, Engineering and Management Sciences

Vol. 5, No. 5, 820-834, 2020

https://doi.org/10.33889/IJMEMS.2020.5.5.064

$$
\begin{aligned}
\max _{\mathrm{w}_{\mathrm{L}}, \alpha_{\mathrm{L}}, \mathrm{T}_{\mathrm{L}}, \mathrm{w}_{\mathrm{H}}, \alpha_{\mathrm{H}}, \mathrm{T}_{\mathrm{H}}} \pi^{\mathrm{S}} & =\mathrm{p} \pi_{L}^{S}\left(w_{L}, \alpha_{L}, T_{L}\right)+(1-p) \pi_{H}^{S}\left(w_{H}, \alpha_{H}, T_{H}\right) \\
& =\mathrm{p}\left[\left(w_{j}-c\right) Q_{L L}+\mathrm{r} \alpha_{L} \int_{0}^{Q_{L L}} \overline{F_{L}}(x) \mathrm{dx}+T_{L}\right]+(1-p)\left[\left(w_{H}-\right.\right. \\
& \text { c) } Q_{H H}+\mathrm{r \alpha}_{H} \int_{0}^{Q_{H H}} \overline{F_{H}}(x) \mathrm{dx}+T_{H} \quad \text { (substituting from Eq. (4) }
\end{aligned}
$$

Substituting $w_{L}, w_{H}$ from Eq. (2), $T_{L}, T_{H}$ from Eq. (7) and Eq. (8) respectively and using expectation theorem viz. $\int_{0}^{y} x f(x) d x=y F(y)-\int_{0}^{y} F(x) d x$ in the above expression of $\pi^{S}$, we get Eq. (9) by rearranging the terms. 